\author{
Авербах М.М. (мл.), Панова Л.В., Губкина М.Ф., Евсеева Н.И. \\ ФГБНУ «Центральный научно-исследовательский институт туберкулеза», Москва, Россия
}

Резюме. Цитолитические молекулы системы врожденного иммунитета гранулизин и кателицидин являются важными защитными факторами при инфицировании микобактериями туберкулеза. Нами получены данные о высоких показателях гранулизина и кателицидина у группы инфицированных МБТ детей и подростков. У больных туберкулезом органов дыхания показано низкое содержание сывороточного кателицидина при деструктивных формах, а гранулизина - при «малых» формах туберкулеза до начала специфической химиотерапии. Проведенная химиотерапия не оказывала влияния на содержание гранулизина и кателицидина в сыворотке у больных с деструктивным туберкулезом, тогда как у больных «малыми» формами (ТВГЛУ/очаговый туберкулез) выявлено достоверное увеличение содержания гранулизина через 6 месяцев лечения и кателицидина - через 3 месяца химиотерапии с последующим возвращением к исходному уровню.

\title{
DYNAMIC CHANGES OF GRANULYSIN AND CATHELICIDIN IN CHILDREN AND ADOLESCENTS WITH DIFFERENT FORMS OF PULMONARY TUBERCULOSIS
}

\author{
Averbakh M.M. (Jr), Panova L.V., Gubkina M.F., Evseeva N.I. \\ Central Research Institute for Tuberculosis, Moscow, Russian Federation
}

Abstract. Granulysin and cathelicidin, the cytolytic molecules of innate immune system are important protective factors during infection with Mycobacterium tuberculosis. We present original data concerning high levels of granulysin and cathelicidin among the group of children and adolescents with latent TB infection.

\author{
Адрес для переписки: \\ Авербах Михаил Михайлович (мл.) \\ ФГБНУ «Центральный научно-исследовательский \\ институт туберкулеза» \\ 107564, Россия, Москва, Яузская аллея, 2. \\ Тел.: 8(499) 785-90-72. \\ Факс: 8 (499) 785-91-08. \\ E-mail:amm50@mail.ru
}

\section{Образец цитирования:}

М.М. Авербах (мл.), Л.В. Панова, М.Ф. Губкина,

Н.И. Евсеева «Динамические изменения гранулизина и кателицидина у детей и подростков, больных различными формами туберкулеза органов дыхания» // Медицинская иммунология, 2018. T. 20, № 5. С. 747-752. doi: 10.15789/1563-0625-2018-5-747-752

(с) Авербах М.М. (мл.) и соавт., 2018

\author{
Address for correspondence: \\ Averbakh Michael M. (Jr) \\ Central Research Institute for Tuberculosis \\ 107564, Russian Federation, Moscow, Yauzskaya all., 2. \\ Phone: 7(499) 785-90-72. \\ Fax: 7(499) 785-91-08. \\ E-mail:amm50@mail.ru
}


Patients with tuberculosis of the respiratory system exhibit significantly lower amounts of serum cathelicidin in destructive forms, as well as granulysin levels in "minor" forms of tuberculosis before starting the specific chemotherapy. The chemotherapy performed did not influence the serum granulysin and cathelicidin contents in patients with destructive tuberculosis, whereas the patients with "minor" forms (TLN/focal tuberculosis) revealed a significant increase in granulysin content after 6 months of treatment, and same trend for cathelicidin concentrations after 3 months of chemotherapy, followed by subsequent return to baseline values.

Keywords: tuberculosis, children, adolescent, innate immunity, granulysin, cathelicidin

\section{Введение}

\section{Актуальность}

Гранулизин и кателицидин, а также другие цитолитические молекулы ( $\beta$-дефензин, перфорин, гранзим) относятся к веществам, обеспечивающим различные механизмы врожденного иммунитета. Гранулизин синтезируется в гранулах активированных цитотоксических $\mathrm{CD} 8^{+} \mathrm{T}$ клетках и NK-клетках в виде молекулы $15 \mathrm{kDa}$ и частично $9 \mathrm{kDa}$ и оказывает цитотоксическое действие на опухолевые клетки и широкий спектр грамположительных и грамотрицательных бактерий и внутриклеточных бактерий. Применительно к M. tuberculosis гранулизин повреждает клеточную стенку через нарушение метаболизма липидов [14]. Кроме того, гранулизин индуцирует экспрессию генов различных провоспалительных цитокинов и хемокинов (RANTES, MCP-1, MCP-3, MIP-1 $\alpha$, IL-10, IL-1, IL-6 и IFN $\alpha$ ). Также показано, что небольшая часть субпопуляции $\mathrm{CD}^{+}{ }^{+} \mathrm{T}-$-клеток может лизировать M. tuberculosis-инфицированные макрофаги с использованием молекул гранулизина и перфорина [7]. Кроме того, показано, что при вакцинации БЦЖ образуются $\mathrm{CD}^{+} \mathrm{T}-$-клетки памяти, обладающие способностью экспрессировать гранулизин и перфорин [8]. В дальнейшем было показано, что у больных туберкулезом детей и подростков имеются Т-клетки памяти с фенотипом $\mathrm{CD}^{+} \mathrm{CD}^{+} 5 \mathrm{RO}^{+}$, специфичные к M. tuberculosis и экспрессирующие гранулизин, причем основным источником являются пролиферирующие Т-клетки памяти с фенотипом $\mathrm{CFSE}^{\text {low }} \mathrm{CD}^{+}{ }^{+} \mathrm{CD} 45 \mathrm{RO}^{+}[10]$.

Кателицидин человека hCAP-18/LL-37 (human cationic antimicrobial protein, $18 \mathrm{kDa}-$ название относится к пептиду 18 кДа, полученному внеклеточным протеолизом из С-конца САР человека [катионный антимикробный белок]) вырабатывается в плоскоклеточном эпителии дыхательных путей, рта, языка, пищевода и кишечника. Кроме того, этот пептид секретируется в поту, слюне, раневой жидкости и в семенной плазме.

Методами иммуногистохимии и гибридизации in situ показана продукция hCAP18/LL-37 моноцитами, Т-лимфоцитами, В-лимфоцитами, NK-клетками, эпителиальными клетками и тучными клетками, что приводит к реализации его основной функции в виде аккумуляции на поверхности бактерий и повреждает их мембраны посредством образования ионных каналов, ведущих к гипоосмотическому лизису микроорганизмов. Он способен индуцировать секрецию хемокинов, включая CXCL8 (IL-8) и CCL2 (MCP-1), которые рекрутируют дендритные клетки, моноциты и нейтрофилы на место повреждения, и увеличивает индуцированную IL-1 секрецию IL-6, IL-10 [1].

Исследования, посвященные клинической значимости содержания гранулизина и кателицидина в сыворотке крови при туберкулезе не многочисленные по сравнению с исследованиями различных звеньев адаптивного иммунитета. Так, Sahiratmadjaa Е. и соавт. [11] показали, что содержание сывороточного гранулизина у взрослых, больных туберкулезом, до начала противотуберкулезной терапии было достоверно низким по сравнению с контрольной группой. При легкой/средней выраженности туберкулезных изменений (по Международной классификации туберкулеза) его количество составляло 1,1 нг/мл $(0,1-11,2)$ и при значительной $-0,9$ нг/мл $(0,1-12,4)$, тогда как в контроле находилось на уровне 2,6 нг/мл $(0,2-44,6)$. Через 2 месяца химиотерапии показатели повышались до 2,7 нг/мл $(0,3-8,5)$ и 2,4 нг/мл $(0,3-14,5)$ и к окончанию лечения составляли 4,1 нг/мл $(1,1-28,8)$ и 3,8 нг/мл $(0,5-22,5)$ соответственно. В аналогичных исследованиях на больных 
туберкулезом детского возраста уровень сывороточного гранулизина до начала лечения составлял 0,45 нг/мл $(0,33-2,98)$, а в контрольной группе был достоверно выше 1,4 нг/мл (0,22-6,00). После 4-месячного курса лечения уровень гранулизина достоверно возрастал и достигал уровня контрольной группы [6]. Прямая антимикробная активность hCAP18/LL-37 показана как в культуре M. tuberculosis, так и на экспериментальной микобактериальной инфекции при интратрахеальном заражении микобактериями (штамм H37Rv) у мышей Balb/c [4]. Исследования о содержании кателицидина в биологических жидкостях у больных туберкулезом единичны. Так, показано увеличение его концентрации в жидкости БАЛ у больных туберкулезом по сравнению со здоровым контролем [3]. Также было показано, что концентрация кателицидина была выше у больных активным туберкулезом при положительном посеве на микобактерии и незначительно снижалась в первые 2 месяца химиотерапии [15]. Однако к настоящему моменту не ясна степень выраженности гранулизина и кателицидина у больных детскоподросткового возраста при деструктивных процессах и «малых» формах туберкулеза, учитывая появляющиеся данные о возможном клиническом применении синтетических аналогов гранулизина и особенно кателицидина в комплексе с терапией витамином Д [12].

Целью настоящего исследования явилось изучение содержания гранулизина и кателицидина плазмы крови у детей и подростков больных раз-

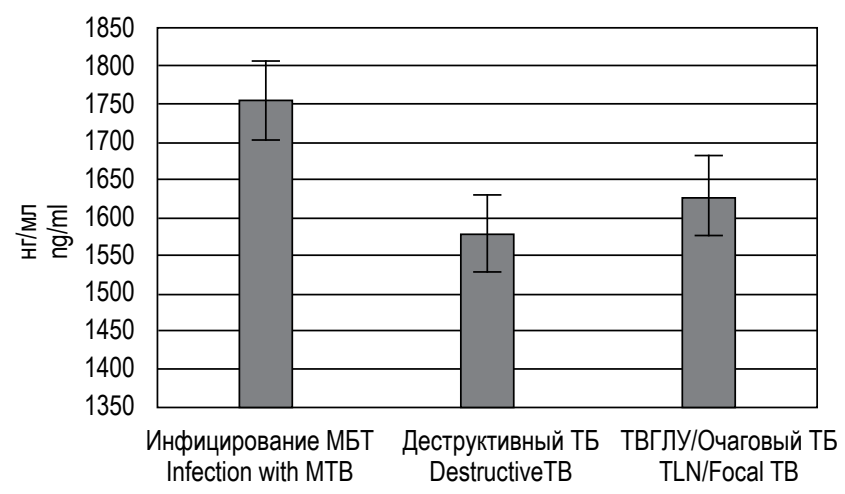

Рисунок 1. Содержание кателицидина до начала лечения

Figure 1. Cathelicidin content before treatment личными формами туберкулеза в процессе противотуберкулезной химиотерапии.

\section{Материалы и методы}

Исследование проведено на 49 больных, разделенных на три группы. В группу больных с деструктивным туберкулезом включено 15 человек в возрасте от 14 до 17 лет. Инфильтративный туберкулез в фазе распада и обсеменения диагностирован у 8 человек, диссеминированный туберкулез в фазе распада - у 3 человек, множественные туберкуломы в фазе распада и обсеменения - у 2 человек, фиброзно-кавернозный туберкулез - у 1 человека и казеозная пневмония - у 1 человека.

В исследование включено 25 больных в возрасте от 3 до 16 лет с «малыми» формами туберкулеза органов дыхания. Туберкулез внутригрудных лимфатических узлов (ТВГЛУ) диагностирован у 11 человек, в том числе с очагами отсева в легочную ткань - 2 человека; очаговый туберкулез легких - 14 человек. Большинство процессов были выявлены в фазе начинающейся кальцинации -10 человек и реже в фазе уплотнения 10 человек, и в фазе инфильтрации - 5 человек.

Группу инфицированных МБТ составили 9 пациентов в возрасте от 5 до 14 лет, обратившихся по поводу контакта с больными туберкулезом и имевших положительные реакции на пробу Манту с 2 ТЕ и Диаскинтест.

Гранулизин определяли в $\mathrm{K}_{3}$ ЭДТА плазме методом иммуноферментного анализа с помощью набора SEB517Hu (Cloud-Clone Corp.) согласно инструкции изготовителя. Диапазон определе-

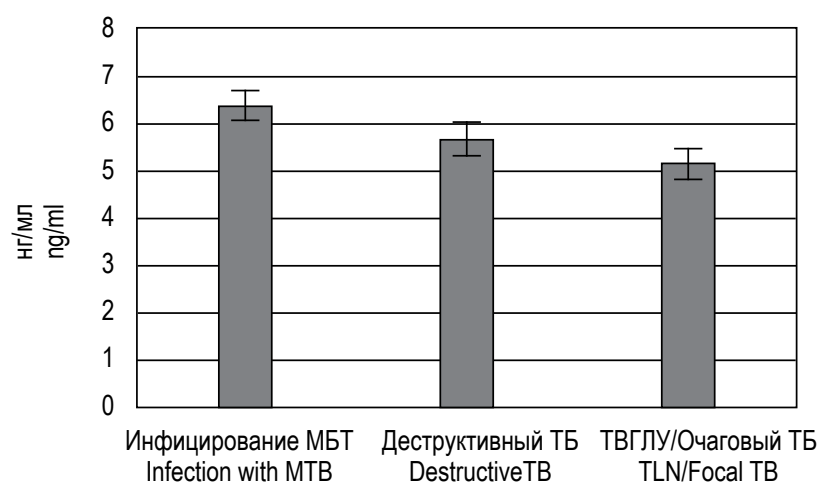

Рисунок 2. Содержание гранулизина до начала лечения Figure 2. Granulosin content before treatment 

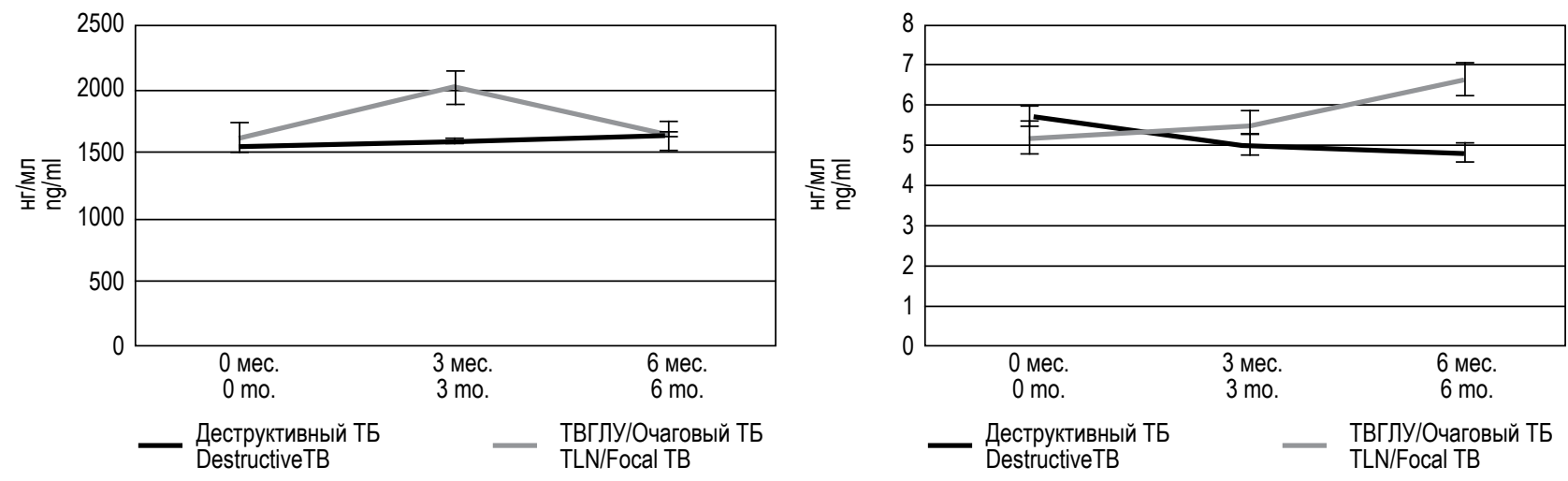

Рисунок 3. Динамические изменения кателицидина и гранулизина

Figure 3. Dynamic changes of cathelicidin and granulosin

ния тест-системы - 0,25-15 нг/мл, минимальная определяемая концентрация - 0,08 нг/мл.

Кателицидин определяли в $\mathrm{K}_{3}$ ЭДТА плазме методом иммуноферментного анализа с помощью набора CEC419Hu (Cloud-Clone Corp.) согласно инструкции изготовителя. Диапазон определения тест-системы 123,5-10 000 нг/мл, минимальная определяемая концентрация 47,4 нг/мл, концентрация белка в ЭДТА плазме у волонтеров составила 161-1041 нг/мл. Результаты обрабатывались статистически с помощью пакета Microsoft Excel.

\section{Результаты и обсуждение}

Сравнение результатов содержания в плазме исследуемых факторов у 3 исследуемых групп показало, что до начала лечения уровень содержания кателицидина не имел достоверных различий между исследуемыми группами (деструктивный, ТВГЛУ/очаговый и инфицированные - 1578,1土123,14,

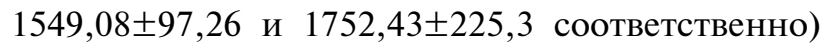
(рис. 1). Содержание гранулизина было более низкое в группе больных с ТВГЛУ/очаговым туберкулезом по сравнению с группой инфициро-

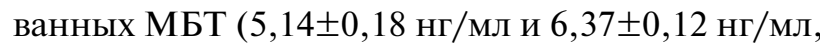
$\mathrm{p}=0,009449$ соответственно) (рис. 2.).

В результате проводимой противотуберкулезной химиотерапии содержание кателицидина в плазме в группе деструктивного туберкулеза не менялось, а в группе больных «малыми» формами туберкулеза достоверно возрастало к 3-м месяцам до 2011,3 $\pm 134,1$ нг/мл ( $=0,042984)$ и затем снижалось до уровня первоначальных показателей (рис. 3).

Содержание гранулизина плазмы крови у больных деструктивным туберкулезом не меня- лось в процессе лечения (до лечения $-6,17 \pm 0,78$,

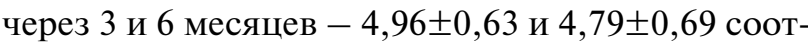
ветственно), а в группе больных «малыми» формами туберкулеза достоверно возрастало к 6-ти

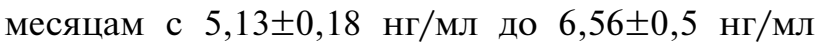
$(\mathrm{p}=0,023631)$, что было сравнимо с показателями у группы инфицированных МБТ пациентов (6,37 $\pm 0,12$ нг/мл).

В экспериментальных и клинических исследованиях по иммунологии туберкулеза клеточным и гуморальным компонентам врожденного иммунитета традиционно отведена вторичная роль, и в основном рассматриваются такие компоненты, как нейтрофильные лейкоциты, Tollподобные рецепторы, NK-клетки и в значительно меньшей степени цитолитические молекулы (гранулизин, кателицидин, $\beta$-дефензин, перфорин, гранзим) [9]. Существует представление, что реакции врожденного иммунитета преимущественно активны на стадии «латентной» фазы туберкулеза при наличии положительных кожных проб и IGRA-тестов и малозначимы при активном функционировании специфического адаптивного иммунитета [5].

Нами получены данные о высоких показателях гранулизина и кателицидина у группы инфицированнных МБТ детей и подростков, и даже достоверно более высоких для гранулизина по сравнению с группой ТВГЛУ/очагового туберкулеза. В процессе лечения в последнем случае уровень фактора достоверно возрастал до уровня группы инфицированных МБТ. Сходная динамика изменения этого фактора у детей представлена в исследовании di Liberto D. и соавт. [6]. Вероятно, это можно связать с возрастанием субпопулиции CD8 T-лимфоцитов, которая увеличивается в результате успешной химиотерапии [2]. 
Нами выявлено достоверное возрастание концентрации кателицидина у больных ТВГЛУ/очаговым туберкулезом через 3 месяца после начала специфической химиотерапии с последующим возвращением к исходному уровню у нелеченых больных. Нам представляется, что данный эффект может возникать вследствие временной активизации моноцитарно-макрофагального звена иммунитета и выработки кателицидина моноцитами. Подобный эффект описан Fiske C.T. и соавт. [7], которые показали подъем продукции хемокинов CCL2 (MCP-1) у этой категории больных в результате проведенного лечения [7].
Таким образом, активная продукция цитолитических молекул гранулизина и кателицидина характерна для инфицированных МБТ пациентов. Значимость продукции этих факторов при деструктивных формах туберкулеза невелика вследствие преобладания реакций Т-клеточного звена адаптивного иммунитета. Однако роль кателицидина и особенно гранулизина более заметна при «малых» формах туберкулеза, где в результате специфической химиотерапии происходит подъем уровня их продукции до уровня инфицированных МБТ пациентов.

\section{Список литературы / References}

1. Agerberth B., Charo J., Werr J., Olsson B., Idali F., Lindbom L., Kiessling R., Jornvall H., Wigzell H., Gudmundsson G.H. The human antimicrobial and chemotactic peptides LL-37 and alpha-defensins are expressed by specific lymphocyte and monocyte populations. Blood, 2000, Vol. 96, pp. 3086-3093.

2. Caccamo N., Meraviglia S., La Mendola C., Guggino G., Dieli F., Salerno A. Phenotypical and functional analysis of memory and effector human CD8 T cells specific for mycobacterial antigens. J. Immunol., 2006, Vol. 177, pp. 1780-1785.

3. Cakir E., Torun E., Gedik A.H., Umutoglu T., Aktas E.C., Topuz U., Deniz G. Cathelicidin and human $\beta$-defensin 2 in bronchoalveolar lavage fluid of children with pulmonary tuberculosis. Int. J. Tuberc. Lung. Dis., 2014, Vol. 18, pp. 671-675.

4. Castañeda-Delgado J., Hernández-Pando R., Serrano C.J., Aguilar-León D., León-Contreras J., RivasSantiago C., Méndez R., González-Curiel I., Enciso-Moreno A., Rivas-Santiago B. Kinetics and cellular sources of cathelicidin during the course of experimental latent tuberculous infection and progressive pulmonary tuberculosis. Clin. Exp. Immunol., 2010, Vol. 161, pp. 542-550.

5. Dheda K., Schwandre S.K., Zhu B., van Zyl-Smit S.K., Zhang V. The immunology of tuberculosis: From bench to bedside. Respirology, 2010, Vol. 15, pp. 433-450.

6. di Liberto D., Buccheri S., Caccamo N., Serena Meraviglia S., Amelia Romano A., di Carlo P., Titon L., Francesco Dieli F., Krensky AM.., Salerno A. Decreased serum granulysin levels in childhood tuberculosis which reverse after therapy. Tuberculosis (Edinb), 2007, Vol. 87, pp. 322-328.

7. Fiske C.T., de Almeida C.N., Shintani A.K., Kalam A., Sterlinga T.R. Abnormal immune responses in persons with previous extrapulmonary tuberculosis in an in vitro model that simulates in vivo infection with Mycobacterium tuberculosis. Clin. Vaccine Immunol., 2012, Vol. 19, pp. 1142-1149.

8. Gansert J.L., Kiessler V., Engele M., Wittke F., Röllinghoff M., Krensky A.M., Porcelli S.A., Modlin R.L., Stenger S. Human NKT cells express granulysin and exhibit antimycobacterial activity. J. Immunol., 2003, Vol. 170, pp. 3154-3161.

9. Korbel D.S., Schneider B.E., Schaible U.E. Innate immunity in tuberculosis: myths and truth. Microbes Infect., 2008, Vol. 10, 995e1004. doi: 10.1016/j.micinf.2008.07.039.

10. Mueller H., Fae K.C., Magdorf M., Ganoza C.A., Wahn U., Guhlich U., Feiterna-Sperling C., Kaufmann S.H.E. Granulysin-expressing $\mathrm{CD}^{+} \mathrm{T}$ cells as candidate immune marker for tuberculosis during childhood and adolescence. PLoS ONE, 2011, Vol. 6, Issue 12, e29367. doi: 10.1371/journal.pone.0029367.

11. Sahiratmadjaa E., Alisjahbanad B., Buccherie S., Di Libertoe D., de Boera T., Adnanc I., van Crevelf R., Kleina M.R., van Meijgaardena K.E., Nelwang R.H.H., van de Vosseb E., Dielie F., Ottenhoff T.H.M. Plasma granulysin levels and cellular interferon- $\gamma$ production correlate with curative host responses in tuberculosis, while plasma interferon- $\gamma$ levels correlate with tuberculosis disease activity in adults. Tuberculosis, 2007, Vol. 87, pp. 312-321.

12. Selvaraj P. Vitamin D, vitamin D receptor, and cathelicidin in the treatment of tuberculosis. Vitam. Horm., 2011, Vol. 86, pp. 307-324. 
13. Soehnlein O., Zernecke A., Eriksson E.E., Rothfuchs A.G., Pam C.T., Herwald H., Bidzhekov K., Rottenberg M.E., Weber C., Lindbom L. Neutrophil secretion products pave the way for inflammatory monocytes. Blood, 2008, Vol. 112, pp. 1461-1567.

14. Krensky A.M., Clayberger C. Biology and clinical relevance of granulysin. Tissue Antigens, 2009, Vol. 73, pp. 193-198.

15. Yamshchikov A.V., Kurbatova E.V., Kumari M., Blumberg H.M., Ziegler T.R., Ray S.M., Tangpricha V. Vitamin D status and antimicrobial peptide cathelicidin (LL-37) concentrations in patients with active pulmonary tuberculosis. Am. J. Clin. Nutr., 2010, Vol. 92, pp. 603-611.

\section{Авторы:}

Авербах М.М. (мл.) - д.м.н., профессор, главный научный сотрудник отдела иммунологии ФГБНУ «Центральный научно-исследовательский институт туберкулеза», Москва, Россия

Панова Л.В. - д.м.н., ведущий научный сотрудник детско-подросткового отдела ФГБНУ «Центральный научно-исследовательский институт туберкулеза», Москва, Россия

Губкина М.Ф. - д.м.н., ведущий научный сотрудник детско-подросткового отдела ФГБНУ «Центральный научно-исследовательский институт туберкулеза», Москва, Россия

Евсеева Н.И. - младший научный сотрудник детскоподросткового отдела ФГБНУ «Центральный научно исследовательский институт туберкулеза», Москва, Россия
Authors:

Averbakh M.M. (Jr), PhD, MD (Medicine), Professor, Main Research Associate, Department of Immunology, Central Research Institute for Tuberculosis, Moscow, Russian Federation

Panova L.V., PhD, MD (Medicine), Senior Research Associate, Pediatric Department, Central Research Institute for Tuberculosis, Moscow, Russian Federation

Gubkina M.F., PhD, MD (Medicine), Senior Research Associate, Pediatric Department, Central Research Institute for Tuberculosis, Moscow, Russian Federation

Evseeva N.I., Junior Research Associate, Pediatric Department, Central Research Institute for Tuberculosis, Moscow, Russian Federation

Received 29.09.2017

Revision received 10.10.2017 Accepted 08.11.2017 